\title{
A new method to reconstruct the ionospheric convection patterns in the polar cap
}

\author{
P. L. Israelevich, A. I. Ershkovich \\ Department of Geophysics and Planetary Sciences, Raymond and Beverly Sackler Faculty of Exact Sciences, \\ Tel Aviv University, Ramat Aviv 69978, Israel \\ E-mail: peter@jupiterl.tau.ac.il
}

Received: 2 July 1998 / Revised: 23 November 1998 / Accepted: 25 November 1998

\begin{abstract}
A new method to reconstruct the instantaneous convection pattern in the Earth's polar ionosphere is suggested. Plasma convection in the polar cap ionosphere is described as a hydrodynamic incompressible flow. This description is valid in the region where the electric currents are field aligned (and hence, the Lorentz body force vanishes). The problem becomes two-dimensional, and may be described by means of stream function. The flow pattern may be found as a solution of the boundary value problem for stream function. Boundary conditions should be provided by measurements of the electric field or plasma velocity vectors along the satellite orbits. It is shown that the convection pattern may be reconstructed with a reasonable accuracy by means of this method, by using only the minimum number of satellite crossings of the polar cap. The method enables us to obtain a reasonable estimate of the convection pattern without knowledge of the ionospheric conductivity.
\end{abstract}

Key words. Ionosphere (modelling and forecasting; plasma convection; polar ionosphere).

\section{Introduction}

The pattern of ionospheric convection at high latitudes can be considered as a snapshot of the whole magnetosphere since it results directly from the magnetosphere-ionosphere coupling and reflects the electric field, electric current and plasma flow throughout the magnetospheric volume. If one neglects parallel electric fields in the magnetosphere and temporal changes of magnetospheric configuration, then the magnetospheric electric field projects along equipotential magnetic field lines

Correspondence to: P. L. Israelevich onto the ionosphere, and causes ionospheric convection as an electric $(\mathbf{E} \times \mathbf{B})$ drift. Under these assumptions, both classical magnetospheric convection schemes due to viscous interaction (Axford and Hines, 1961) and to magnetic reconnection (Dungey, 1961) give rise to two convection cells at ionospheric altitudes. These two cells indeed are the dominant feature of the convection observed at high latitudes (e.g. Heppner, 1977; Heppner and Maynard, 1987; Holt et al., 1987; Richmond et al., 1988). It is believed that the antiSunward convection in the polar cap corresponds to the Sunward convection in the magnetosphere, and that the Sunward convection at low latitude parts of the cells is a projection of the antiSunward flows in the magnetospheric boundary layer. The appearance of Sunward convection in the polar cap during the periods of northward interplanetary magnetic field (IMF) makes the convection pattern more complicated. It may be explained by means of additional convection cells (e.g. Burke et al., 1979; Potemra et al., 1984; Reiff and Burch, 1985) or by strong distortion of the common two-cell pattern (Heppner and Maynard, 1987). In any case, it reflects important changes in the outer magnetosphere resulting from interaction with the solar wind, since the polar ionosphere is electrically coupled with the magnetospheric regions of interest via magnetic field lines. This coupling defines the ionospheric convection not only in the idealized case of equipotential stationary magnetic field lines, but also in the presence of parallel electric fields and temporal changes of magnetospheric configuration which make the mutual mapping of ionospheric and magnetospheric processes much more complicated (Lockwood et al., 1990; Hesse et al., 1997).

Numerous studies of the average convection patterns and their dependence on solar wind conditions have been undertaken using satellite data on the electric field, plasma velocity, field-aligned currents, radar observations or ground-based measurements of magnetic field disturbance associated with convection (e.g. Heppner, 1977; Heppner and Maynard, 1987; Banks et al., 1984; Clauer and Banks, 1986; Friis-Christensen et al., 1985; 
Gizler et al., 1979; Heelis, 1984; Holt et al., 1987; Mishin, 1977; Troshichev, 1982; Feldstein et al., 1984; Hairston and Heelis, 1990; Papitashvili et al., 1994; Rich and Hairston, 1994; Weimer, 1995; Rouhoniemi and Greenwald, 1996). Along with studies of average convection revealing the general picture of solar wind/ magnetosphere coupling, it is important to obtain the 'instantaneous' convection pattern which reflects the behaviour of the magnetosphere at a certain specific moment. Attempts to reconstruct instantaneous convection patterns have been undertaken by combining simultaneous satellite measurements of the electric field and plasma drift (e.g. Heelis et al., 1983), by radar measurements of the plasma velocity (e.g. Sofko et al., 1995) or by direct calculation using the ground magnetic field perturbations (e.g. Kamide et al., 1981; Mishin et al., 1986). Marklund et al. (1987) derived instantaneous pictures of high-latitude convection using instantaneous UV auroral images and average distributions of field aligned currents and ionospheric conductivity. Comprehensive technique (AMEI) has been developed by Richmond and Kamide (1988) for mapping convection in the polar ionosphere by fitting sets of localized ground-based and satellite data on magnetic perturbations and electric fields.

In the present work, we propose a simple method to reconstruct the instantaneous convection pattern using, as input data, only the electric field (or the plasma velocity) vector measurements along polar orbits. The method is based on the hydrodynamic description, which, to our knowledge, has not yet been applied to high-latitude ionospheric convection. A brief description of the method is given in Sect. 2. Section 3 considers the application of the method to model convection patterns. It is shown that the convection pattern may be reconstructed with a reasonable accuracy using only the minimum number of satellite crossings of the polar cap.

\section{Model}

We will use the following assumptions. First of all, we neglect the curvature of the ionosphere assuming it to be a horizontal plane. The main geomagnetic field $\mathbf{B}_{0}$ is assumed to be constant in the polar cap and parallel to the vertical axis $Z$. Finally, we assume that the closure of field-aligned currents occurs at lower altitudes of 100 $200 \mathrm{~km}$. Under these assumptions $\partial / \partial z=0$ at the altitudes $\sim 1000 \mathrm{~km}$, and the problem becomes twodimensional. As the transverse conductivity is almost zero at these altitudes, and the magnetic field lines are equipotential, the plasma convection velocity approximately coincides with the electric drift velocity

$\mathbf{v}=c \frac{\mathbf{E} \times \mathbf{B}}{\mathbf{B}^{2}}$

The magnetic field perturbation due to field aligned currents is small: $\Delta \mathbf{B} \ll \mathbf{B}_{0}$, hence

$\mathbf{v}=c \frac{\mathbf{E} \times \mathbf{B}_{0}}{\mathbf{B}_{0}^{2}}$
On the other hand, the Lorentz body force $1 / c$ $\mathbf{j} \times \mathbf{B}=0$, since electric currents at these altitudes are field aligned. Hence, a magnetohydrodynamic flow reduces to a hydrodynamic one, and may be described by the Euler equation

$\frac{\partial \mathbf{v}}{\partial t}+(\mathbf{v} \nabla) \mathbf{v}=-\frac{1}{\rho} \nabla p$

The ionospheric convection is subsonic, so that the flow is incompressible, and hence, one can introduce a stream function $\Psi\left(v_{x}=\partial \Psi / \partial y ; v_{y}=-\partial \Psi / \partial x\right)$, which obeys the following equation (e.g. Landau and Lifshits, 1959):

$\frac{\partial}{\partial t} \nabla^{2} \Psi-\frac{\partial \Psi}{\partial x} \frac{\partial}{\partial y} \nabla^{2} \Psi+\frac{\partial \Psi}{\partial y} \frac{\partial}{\partial y} \nabla^{2} \Psi=0$

With $\partial / \partial t=0$, stream function $\Psi$ is related to the electric potential $\Phi$ in the polar cap by means of Eq. (2):

$\Psi= \pm \frac{c}{\mathbf{B}_{0}} \Phi$

where the sign is positive in the southern polar cap, and negative in the northern cap.

Thus, for a steady state $\partial / \partial t=0$, the electric potential $\Phi$ satisfies the following equation

$-\frac{\partial \Phi}{\partial x} \frac{\partial}{\partial y} \nabla^{2} \Phi+\frac{\partial \Phi}{\partial y} \frac{\partial}{\partial x} \nabla^{2} \Phi=0$

The meaning of this equation is quite clear: the electric field is parallel to the gradient of the electric charge density $\rho_{e}=-\nabla^{2} \Phi$, or, in other words, $\rho_{e}=\rho_{e}(\Phi)$. If the vector electric field measurements are available from one or more satellites, one can subdivide the polar cap (Fig. 1) into several regions whose boundaries are the low latitude boundary at which $\Phi=0$ and $\partial \Phi / \partial n=0$ or the satellite orbits. Two components of the electric field vector measured by a satellite also provide $\Phi$ and $\partial \Phi / \partial n$ along the satellite trajectory. Hence, the polar cap is divided into several parts (two parts if only one satellite orbit is available), with the corresponding boundary conditions for $\Phi$ and $\partial \Phi / \partial n$.

It is obvious that the solution of the Eq. (6) with boundary conditions for $\Phi$ and $\partial \Phi / \partial n$ is not unique. However, among the variety of solutions, a unique solution exists. For this solution each point inside the region is connected with the boundary of the region by means of a stream line, i.e. closed loops of stream lines which belong entirely to the region are absent. The simplest way to find this unique solution is as follows.

Contrary to the boundary value problem described, the Cauchy problem for Eq. (4), with given initial condition for $\Psi\left(\mathrm{t}_{0}\right)$ and boundary conditions for $\Phi$ and $\partial \Phi / \partial n$ has a unique solution (Lions, 1969). Thus, the set of solutions of Eq. (6) may be obtained as solutions of Eq. (4) with $t \rightarrow \infty$ (when $\partial / \partial t \rightarrow 0$ and $\Psi$ is related to $\Phi$ via Eq. 5), for given boundary conditions and various initial conditions inside the region. For the initial condition $\Psi=0$ at $t=0$, we obtain a unique solution with no loops of stream lines inside the region. This solution corresponds to real convection pattern if 


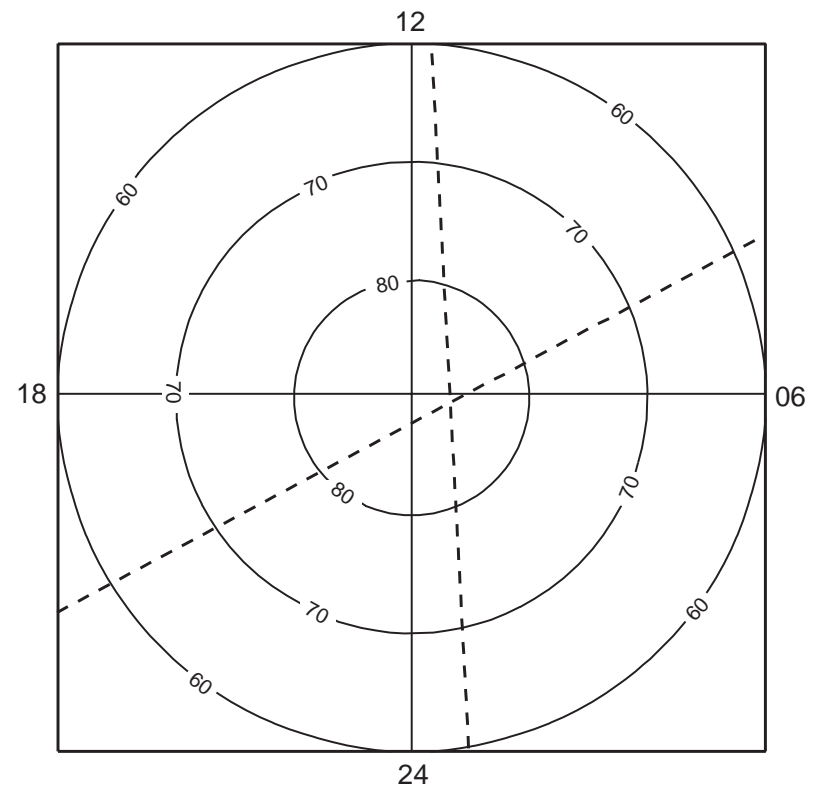

Fig. 1. Polar cap subdivided into several regions by satellites orbits. Boundaries, at which $\Phi$ and $\partial \Phi / \partial n$ are assumed to be known, are satellites trajectories (thick dashed lines) and low latitude boundary of the polar cap (thick solid line)

the boundaries intercept all the stream lines. Such a procedure eliminates the ionospheric conductivity from consideration, so that information of the conductivity distribution is not needed for determination of the convection pattern. However, the perturbation of the conductivity may result in the appearance of the convective cell where stream lines do not cross the boundaries. In this case, the convection distortion due to conductivity changes cannot be revealed by the proposed procedure.

Thus, in order to plot a convection pattern in the polar cap, it is sufficient to know the electric field (or the plasma velocity) vector along trajectories which cross all (or almost all) the stream lines. This geometry can be barely reached by only one satellite crossing, but, as will be shown, two crossings give quite satisfactory results.

\section{Discussion}

The use of the method described requires a clarification of the following questions: (a) which crossing geometry results in a satisfactory restoration of the convection in the polar cap ionosphere? (b) When it is possible to use the assumption of steady state convection satisfying Eq. (6)?

In order to study the first question, we have constructed two model convection patterns which satisfy Eq. (6). The two cell convection pattern is shown in Fig. $2 \mathrm{a}$ (model 12). Figure $2 \mathrm{~b}$ gives the distribution of the electric potential corresponding to four cell convection (model 123). These distributions are given on a grid of $26 \times 26$. Both stream function and its normal derivative vanish $(\Phi=\partial \Phi / \partial n=0)$ at the boundary of the box. We have subdivided the whole region into several parts by straight lines simulating satellite trajectories. Model values for $\Phi$ and $\partial \Phi / \partial n$ have been taken along the lines as the boundary conditions. The boundary value problem for Eq. (6) has been solved numerically for each part, and the results of calculation have been compared with the model.
Model 12

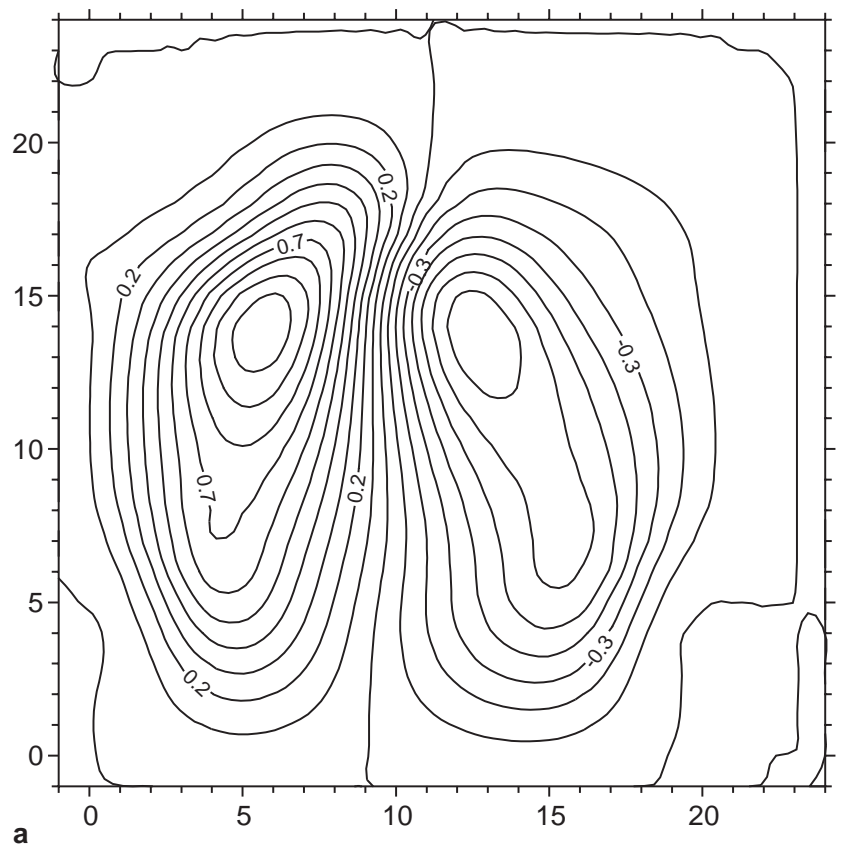

Model 123

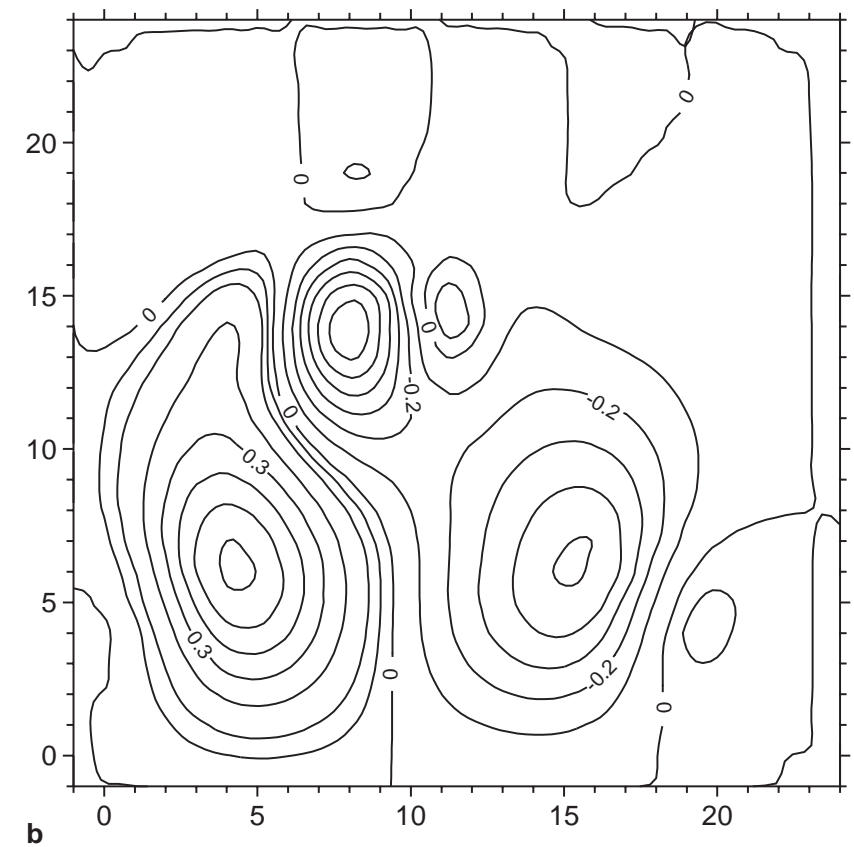

Fig. 2a, b. Model convection pattern for a 2-cell and b 4-cell convection 


\subsection{One orbit}

For the first case we have chosen a 'satellite trajectory' along the line $y=10.5$, which means that the stream function $\Psi$ is known for $y=10$ and $y=11$. Now our box is divided into two regions $-1<x<24,-1<y<$ 11 and $-1<x<24,10<y<24$. Equation (6) has been solved for both regions with known boundary conditions. Reconstructed convection patterns are shown in Fig. 3. Straight lines show the simulated 'satellite trajectory'. Figure $3 \mathrm{a}$ gives the calculated distribution of the electric potential for the two cell model 12. The results for the model 123 (four cells) are reproduced in Fig. 3b. Restored patterns differ significantly from the initial patterns since the chosen 'satellite trajectory' does not cross all the stream lines. However, even in this case for only one orbit, the general topology of the flow is reproduced. Two convection cells can be seen for the reconstructed model 12. As to the model 123, three convection cells are clearly seen in Fig. 3b, and even a certain signature of the fourth cell can be traced, despite the fact that the simulated 'satellite trajectory' did not cross the stream lines which belong to this cell. Much better results can be achieved if we use the data on $\Phi$ and $\partial \Phi / \partial n$ along two lines (simulation of two satellite polar cap crossing) which cross most of the stream lines.

\subsection{Two parallel orbits}

For this case we have chosen two trajectories along lines $y=7.5$ and $y=16.5$. Now the polar cap is subdivided into three regions: $-1<x<24, \quad-1<y<8$; $-1<x<24, \quad 7<y<17$ and $-1<x<24$, $16<y<24$. Solutions of Eq. (4) for these three regions are shown in Fig. 4a (model 12) and Fig. 4b (model 123). These solutions are indicative of rather accurate reconstructions of the initial model convection patterns.

\subsection{Two perpendicular orbits}

Finally, we have considered two mutually perpendicular trajectories along the lines $y=11.5$ and $x=11.5$. These trajectories subdivide the polar cap into four regions: $-1<x<12,-1<y<12 ;-1<x<12$, $11<y<24 ; \quad 11<x<24, \quad-1<y<12 \quad$ and $11<x<24,11<y<24$, where Eq. (4) has been solved. The results of the convection patterns reconstruction are shown in Fig. 5a for model 12 and in Fig. $5 \mathrm{~b}$ for model 123. Again, the reconstructed convection patterns correspond fairly well to the model patterns.

Thus, in order to obtain a good reconstruction, we need trajectories which cross as many convection stream lines as possible. If only one orbit is available, usually the best trajectory is the dawn-dusk orbit passing through the pole. In this case, the reconstruction is satisfactory only in the closest vicinity of the orbit and, hence it can be used, e.g., for revealing throat-like structures when the satellite moves not very far from them. For the case of two orbits, the optimal situations are similar to those shown in Figs. 4 and 5. Two orbits should be approximately parallel, dividing the polar cap
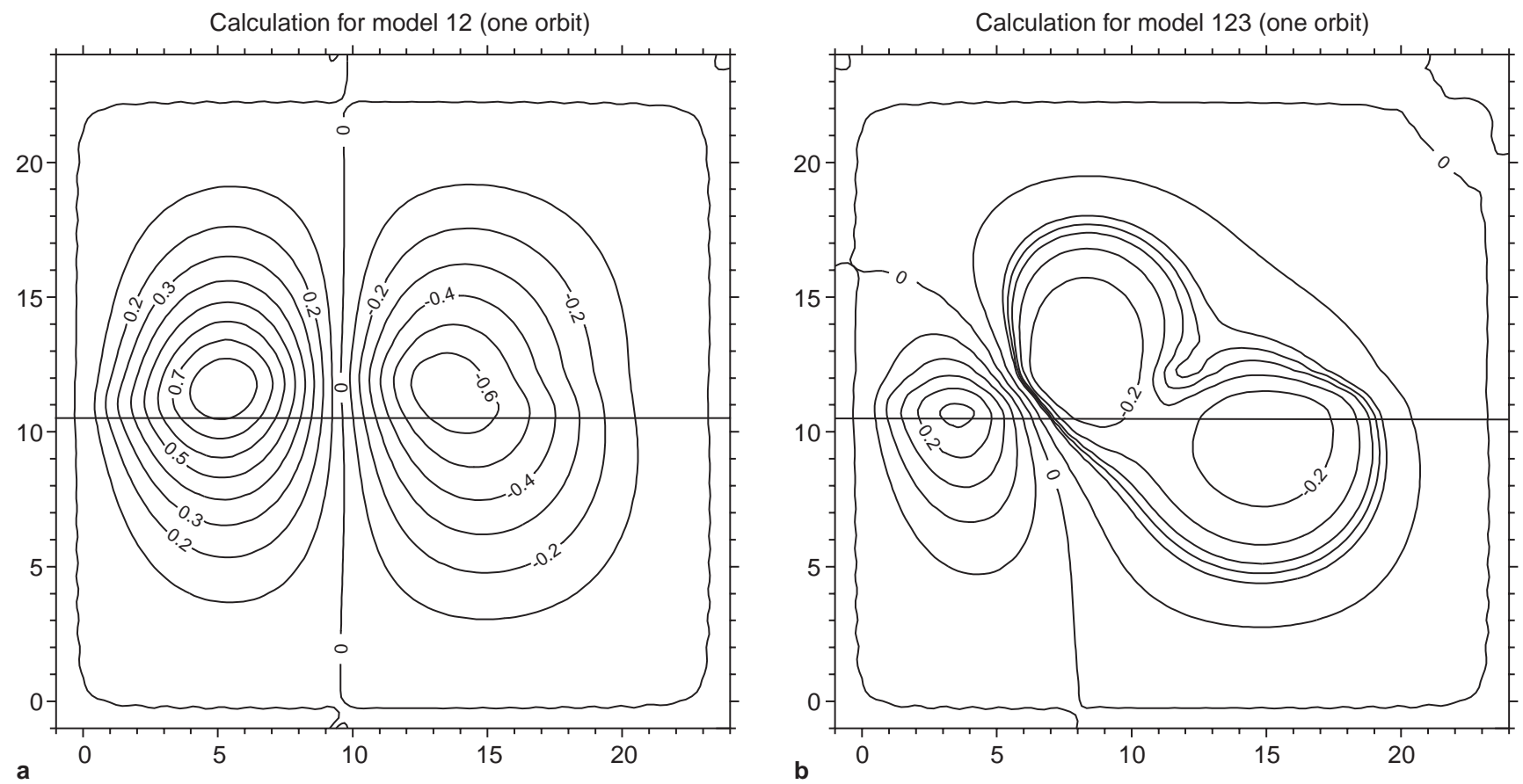

Fig. 3a, b. Convection patterns reconstructed by using the data along a single line (one orbit case). a 2-cell convection; b 4-cell convection 

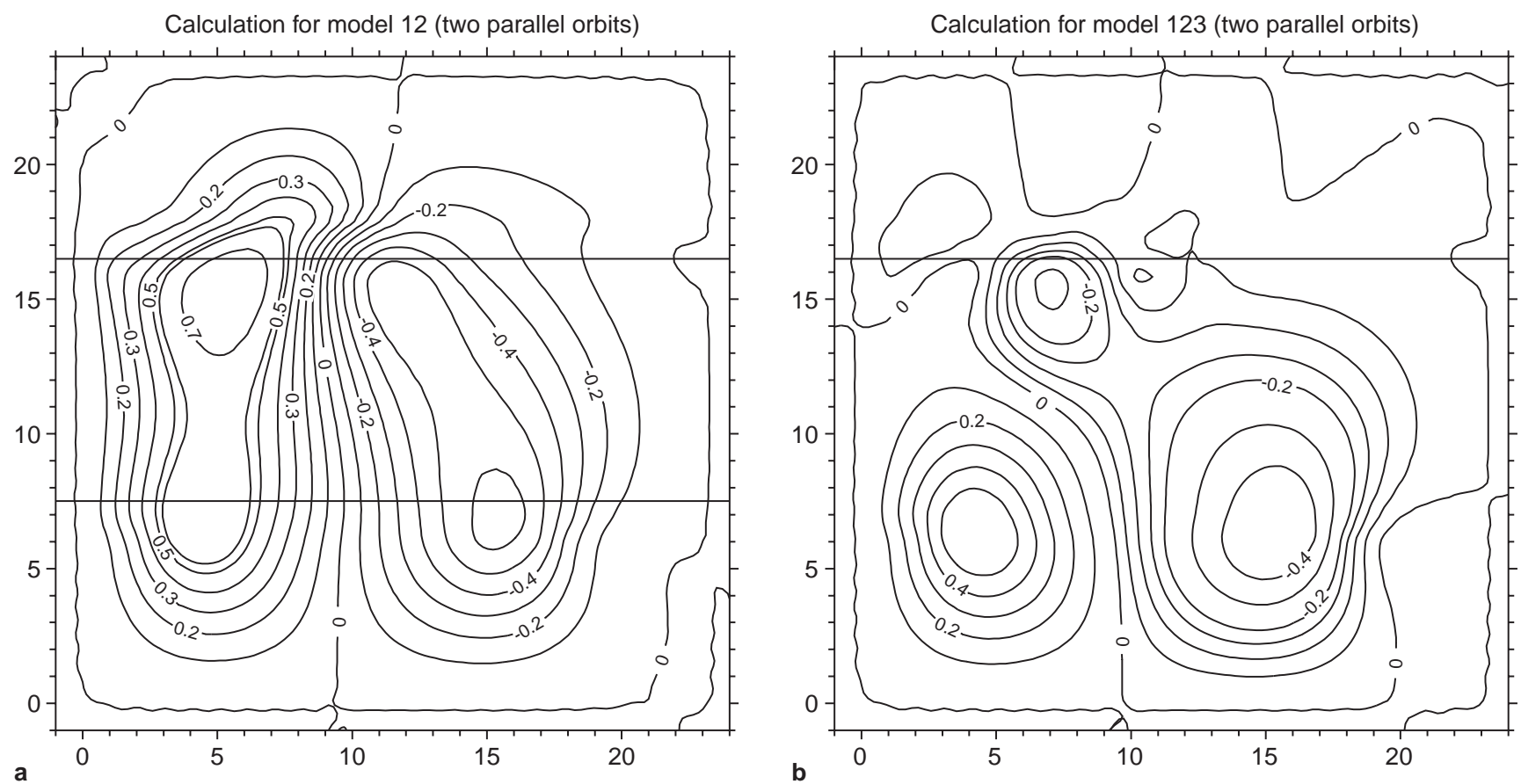

Fig. 4a, b. Convection patterns reconstructed by using the data along two parallel lines (two orbit case). a 2-cell convection; b 4-cell convection
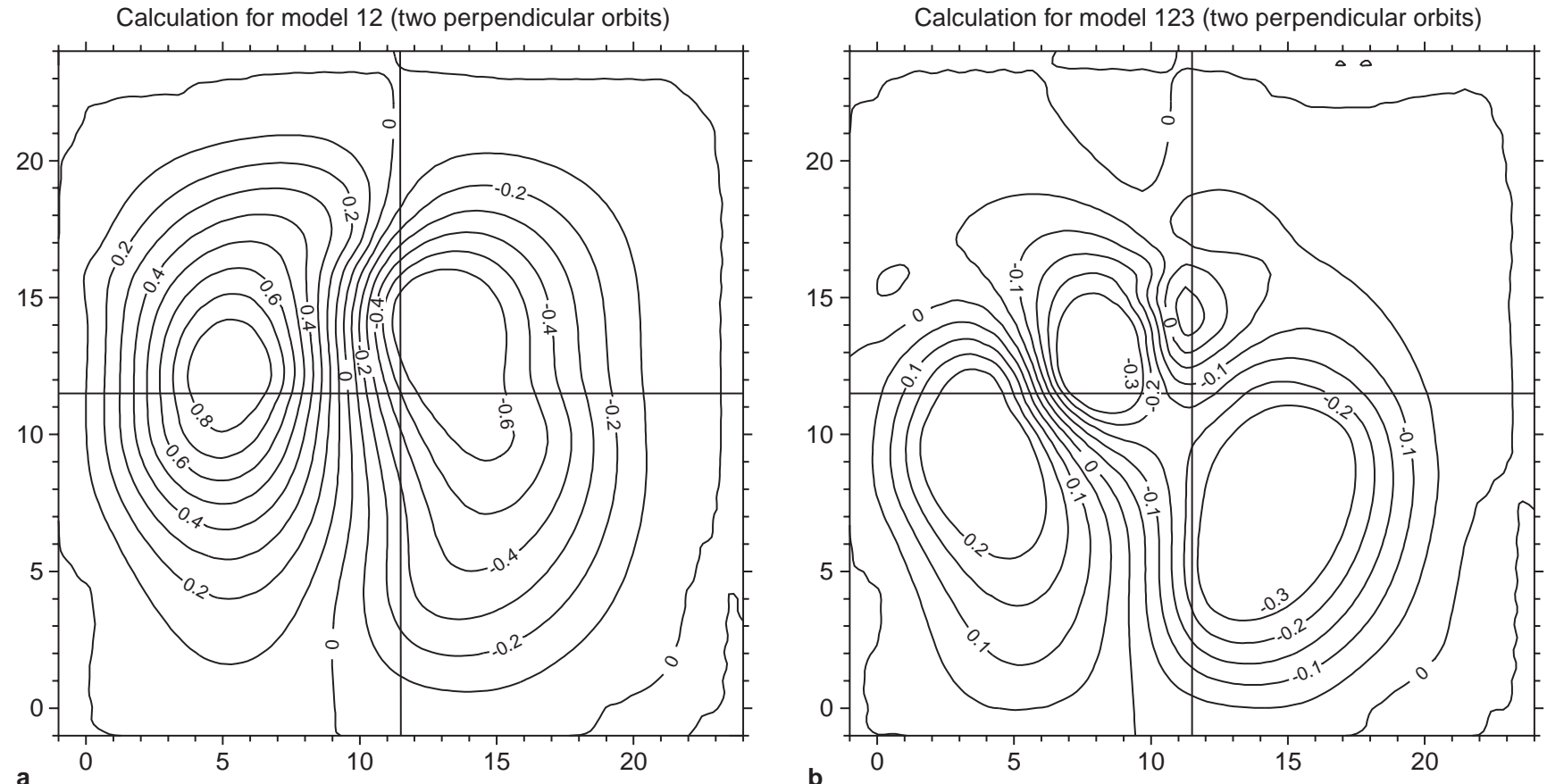

Fig. 5a, b. Convection patterns reconstructed by using the data along two perpendicular lines (one orbit case). a 2-cell convection; b 4-cell

into approximately equal parts, or, another preferable situation, two orbits should be mutually perpendicular and pass over the pole.

Ionospheric convection is highly variable. Therefore, instantaneous convection patterns are very important. This variability does not necessarily contradict our assumption that the flow is steady state. In fact, we assumed that $\nabla \times \mathbf{E}=0$ in the polar cap. If the convection electric field does not penetrate to the low latitude region, the reasonable check for this assumption is to study whether or not $\int \mathbf{E d} \mathbf{l}$ becomes negligible over the polar cap region by using available experimental data.

\section{Conclusion}

We propose to describe the convection in the polar cap ionosphere as a hydrodynamic incompressible flow. This 
description is valid in the regions where the electric currents are field aligned, as $\mathbf{j} \times \mathbf{B}=0$. A unique solution of hydrodynamic equation for stream function exists for each region of the polar cap surrounded by segments of satellite trajectories, if the electric field vector components, measured along the trajectories, are taken as boundary conditions and if there are no closed loops of stream lines which lie entirely in the region. Thus, in case when satellite trajectories cross all (or almost all) the stream lines, merging of solutions for all regions corresponds rather well to the 'true' convection picture in the polar cap and may be considered as a reconstructed 'effective' convection pattern.

Acknowledgement. This work was supported by a grant from the Adler Foundation.

Topical Editor D. Alcaydé thanks D. R. Weimer and J. Foster for their help in evaluating this paper.

\section{References}

Axford, W. I., and C. O. Hines, A unifying theory of high latitude geophysical phenomena, Can. J. Phys., 39, 1433, 1961.

Banks, P. M., T. Araki, C. R. Clauer, J. P. St. Maurice, and J. C. Foster, The interplanetary electric field, cleft currents and convection in the polar caps, Planet. Space Sci., 32, 1551, 1984.

Burke, W. J., M. C. Kelly, R. C. Sagalyn, M. Smiddy, and S. T. Lai, Polar cap electric field structure with a northward interplanetary magnetic field, Geophys. Res. Lett., 6, 21-24, 1979.

Clauer, C. R., and P. M. Banks, Relationship of the interplanetary electric field to the high-latitude ionospheric electric field and currents: observations and model simulation, J. Geophys. Res., 91, 6959-6971, 1986.

Dungey, J. W., Interplanetary magnetic field and the auroral zones, Phys. Rev. Lett., 6, 47-78, 1961.

Feldstein, Y. I., A. E. Levitin, D. S. Faermark, R. G. Afonina, and B. A. Belov, Electric fields and potential patterns in the highlatitude ionosphere for different situations in interplanetary space, Planet. Space Sci., 32, 907-923, 1984.

Friis-Christensen, E., Y. Kamide, A. D. Richmond, and S. Matsushita, Interplanetary magnetic field control of high latitude electric fields and currents determined from Greenland magnetometer data, J. Geophys. Res., 90, 1325-1338, 1985.

Gizler, V. A., V. S. Semenov, and O. A. Troshichev, Electric fields and currents in the ionosphere generated by field-aligned currents observed by TRIAD, Planet. Space Sci., 27, 223, 1979.

Hairston, M. R., and R. A. Heelis, Model of high-latitude ionospheric convection pattern during southward interplanetary magnetic field using DE2 data, J. Geophys. Res., 95, 23332343, 1990.

Heelis, R. A., The effects of interplanetary magnetic field orientation on dayside high-latitude ionospheric convection, J. Geophys. Res., 89, 2873-2880, 1984.

Heelis, R. A., J. C. Foster, O. de la Beaujardiere, and J. Holt, Multistation measurements of high-latitude ionospheric convection, J. Geophys. Res., 88, 10, 111-10, 121, 1983.

Heppner, J. P., Empirical models of high latitude electric field, J. Geophys. Res., 82, 1115-1125, 1977.

Heppner, J. P., and N. C. Maynard, Empirical high latitude electric field models, J. Geophys. Res., 92, 1115-1125, 1987.
Hesse, M., J. Birn, and R. A. Hoffman, On the mapping of ionospheric convection into the magnetosphere, J. Geophys. Res., 102, 9543-9551, 1997.

Holt, J. M., R. H. Wand, J. V. Evans, and W. L. Oliver, Empirical models for the plasma convection at high latitudes from Millstone observations, J. Geophys. Res., 92, 203-212, 1987.

Kamide, Y., A. D. Richmond, and S. Matsushita, Estimation of ionospheric electric fields, ionospheric currents, and fieldaligned currents from ground magnetic records, J. Geophys. Res., 86, 801-813, 1981.

Landau, L. D., and E. M. Lifshits, Fluid mechanics, Pergamon, London, 1959.

Lions, J. L., Quelque methodes de resolution des problemes aux limites non lineaires, Dunod Gauthier-Villars, Paris, 1969.

Lockwood, M., S. W. H. Cowley, and M. P. Freeman, The excitation of plasma convection in the high-latitude ionosphere, J. Geophys. Res., 95, 7961-7972, 1990.

Marklund, G. T., L. G. Blomberg, T. A. Potemra, J. S. Murphree, F. J. Rich, and K. Stasiewicz, A new method to derive "instantaneous" high-latitude potential distributions from satellite measurements including auroral imager data, Geophys. Res. Lett., 14, 439-442, 1987.

Mishin, V. M., High-latitude geomagnetic variations and substorms, Space Sci. Rev., 20, 621-675, 1977.

Mishin, V. M., S. B. Lunyushkin, B. S. Shirapov, and W. Baumjohann, A new method for generating instantaneous ionospheric conductivity models using ground-based magnetic data, Planet. Space Sci., 34, 713-722, 1986.

Papitashvili, V. O., B. A. Belov, D. S. Faermark, Y. I. Feldstein, S. A. Golyshev, L. I. Gromova, and A. E. Levitin, Electric potential patterns in the northern and southern regions parametrized by the interplanetary magnetic field, J. Geophys. Res., 99, 13, 25113, 262, 1994.

Potemra, T. A., L. J. Zanetti, P. F. Bythrow, A. T. Y. Lui, and T. Iijima, $B_{y}$-dependent convection patterns during northward interplanetary magnetic field, J. Geophys. Res., 89, 9753-9760, 1984.

Reiff, P. H., and J. L. Burch, IMF $B_{\mathrm{y}}$ dependent plasma flow and Birkeland currents in the dayside magnetosphere 2. A global model for northward and southward IMF, J. Geophys. Res., 90, 1595-1609, 1985.

Rich, F. J., and M. Hairston, Large-scale convection patterns observed by DMSP, J. Geophys. Res., 99, 3827-3844, 1994.

Richmond, A. D., and Y. Kamide, Mapping electrodynamic features of the high-latitude ionosphere from localized observations: technique, J. Geophys. Res., 93, 5741-5759, 1988.

Richmond, A. D., Y. Kamide, B.-H. Ahn, S.-I. Akasofu, D. Alcayde, M. Blanc, O. de la Beaujardiere, D. S. Evans, J. C. Foster, E. Friis-Christensen, T. J. Fuller-Rowell, J. M. Holt, D. Knipp, H. W. Kroehl, R. P. Lepping, R. J. Pellinen, C. Senior, and A. N. Zaitzev, Mapping electrodynamic features of the high-latitude ionosphere from localized observations: Combined incoherentscatter radar and magnetometer measurements for January 18 19, 1984, J. Geophys. Res., 93, 5760-5776, 1988.

Rouhoniemi, J. M., and R. A. Greenwald, Statistical patterns of high-latitude convection obtained from Goose Bay HF radar observations, J. Geophys. Res., 101, 21 743-21 763, 1996.

Sofko, G. J., R. Greenwald, and W. Bristow, Direct determination of large-scale magnetosphere field-aligned currents with SuperDARN, Geophys. Res. Lett., 22, 2041-2044, 1995.

Troshichev, O. A., Polar magnetic distubances and field-aligned currents, Space Sci. Rev., 32, 275-360, 1982.

Weimer, D. R., Models of high-latitude electric potentials derived with least error fit of spherical harmonic coefficients, J. Geophys. Res., 100, 19 595-19 607, 1995. 